\title{
Prevention of suicide behind bars: first Italian results
}

\author{
Annalisa Frangione 1 , Letizia Bracali ${ }^{2}$, Luca Rosi ${ }^{2}$, Maria Mancino ${ }^{2}$, Marisa Meschi ${ }^{2}$, Nicola Nante ${ }^{3,4}$ \\ and Gianmarco Troiano ${ }^{3,4^{*}}$ (D)
}

\begin{abstract}
Background: The reduction of suicides in jails and prisons is an international priority and, after the publication of a report about the necessity to prevent the suicide risk, in Tuscany (Italy) was created a new biphasic protocol. The aim of our study was to show the preliminary results after the introduction of this protocol in the Penitentiary of Pistoia.

Methods: We conducted an ecological pilot study from April to December 2016. In the Penitentiary of Pistoia, a multidisciplinary staff collected socio-demographic and clinical information of the new inmates, and estimated the suicide risk administering the Arboleda-Florez Checklist.

Results: Ninety-three new prisoners (all males) were conducted in the Penitentiary of Pistoia: 12 (12.90\%) came from another prison; 81 (87.09\%) were free before the arrival. 16 (17.2\%) were homeless, 52 (55.91\%) were unemployed, 1 (1.07\%) was retired. 32 declared to use drugs; 7 of them declared also the alcohol abuse. Three detainees claimed only the alcohol abuse. 9 prisoners were already assisted by the Service for Drug Addiction when they have been arrested. 77 (82.79\%) were positive for at least 1 item of the Arboleda-Florez Checklist. The measures of great surveillance were disposed for 67 prisoners. Three were the measures of Greatest Surveillance for high suicide risk. 13 inmates needed a specific pharmacological treatment prescribed by a psychiatrist. A therapy for mild anxiety and insomnia was prescribed in 29 cases: 21 after the first visit; 8 later. A psychological support was furnished to 23 prisoners who didn't need the prescription of psychotropic medication, but only an emotional support.

Conclusions: Our pilot study showed that the biphasic protocol could be able to manage in a good way the suicide risk, in fact no suicide occurred in the examined period of time. However, studies covering longer periods of time and involving other realities are needed to give more reliable results about its real efficacy.
\end{abstract}

Keywords: Suicide, Prison, Prevention, Mental health, Italy

\section{Introduction}

About 10 suicides per 10,000 inmates, and about 150 attempted suicides for 10,000 inmates occur every year In Italy (Frangione et al., 2016). The reduction of suicides in jails and prisons is an international priority (WHO, 2014) and a lot of countries have national standards and guidelines for suicide prevention in custodial settings (Daigle et al., 2007). Suicide is a complex phenomenon (Troiano et al., 2017) and is one of the most common causes of death in custody worldwide, with rates

\footnotetext{
* Correspondence: gianmarco.troiano@student.unisi.it; gianmarco89@hotmail.it

${ }^{3}$ Post Graduate School of Public Health, University of Siena, Siena, Italy ${ }^{4}$ Department of Molecular and Developmental Medicine, Area of Public Health, University of Siena, 2 Via A. Moro, 53100 Siena, Italy Full list of author information is available at the end of the article
}

substantially higher than in the general population (Fazel et al., 2008). As previous studies demonstrated, several clinical, demographic, criminological factors are associated with suicide in prisoners, the most important being occupation of a single cell, recent suicidal ideation, a history of attempted suicide, and having a psychiatric diagnosis or history of alcohol use problems (Fazel et al., 2008).

Studies in Germany (Opitz-Welke et al., 2013), Italy (Marzano et al., 2016), and other countries in the European Union (Rabe, 2012) as well as Australia (Kariminia et al., 2007) and the US (Baillargeon et al., 2009) suggested that current suicide prevention strategies need to be improved in order to better meet the complex needs of this population (Marzano et al., 2016). Successful intervention programs, designed to identify individuals particularly at 
risk and to assist them through intervention, confirm that prisoners are a group especially at risk for suicide (Felthous, 2011; Gore, 1999). More than 50\% of U.S. jail suicide victims were men, white, unmarried, under 28 years, charged with minor or drug-related offenses, and intoxicated with drugs or alcohol. Suicides significantly occurred in isolation. Psychiatric diagnosis, alcohol abuse, taking psychotropic medication, and suicidal ideation were also positively correlated (Felthous, 2011; Mercurio et al., 2016a; Mercurio et al., 2016b; Stefania Milione et al., 2016; Gambaro et al., 2014a; Gambaro et al., 2014b; Katia Guerrini et al., 2013; Roda et al., 2013; Mercurio et al., 2017). Psychosis, depression, and substance abuse are factors frequently found among inmates (Fazel et al., 2011), and that could increase the suicide risk. The commonest method of suicide is by hanging (Shaw et al., 2004).

In 2013 the National Bioethics Committee for Health in Prison published a report and established the absolute necessity to create specific protocols to prevent suicide risk. The Regional Council of Tuscany (Italy) affirmed the necessity of a synergic work between health personnel and operators of prisons to adopt this kind of measures: this led to the creation of a new biphasic protocol (Frangione et al., 2016). The aim of our study was, therefore, to show the preliminary results after the introduction of this protocol in the Penitentiary of Pistoia (Italy).

\section{Methods}

We conducted an ecological pilot study from April to December 2016 in the Penitentiary of Pistoia. The multidisciplinary staff, created according to the protocol (2014), had to identify the needs of new inmates in order to prepare specific measures to prevent the discomfort and self harm, as well as to manage and monitor the risk of suicide. The multidisciplinary team was composed by the director of the Penitentiary, the Director of the Local Health Unit (or his delegate), a psychiatrist, a psychologist, by educators and by the Head of the Penitentiary Police (or his delegate). If necessary, other professionals such as operators of the Service for Drug Addiction (SerT), nurses, social workers and cultural mediators were included in the staff. The multidisciplinary staff met weekly and prepared a special report containing information about the prisoners and the measures / actions that should be done or revoked. If necessary, the staff met "in emergency" with the operators available at that time.

For all the new prisoners were collected: sociodemographic information (age, citizenship, residence, job) and clinical information (the presence of psychiatric disorders, the use of substances and / or alcohol, the suicidal risk) and were ordered, if necessary, specific interventions for their best management: great surveillance, prescription of psychotropic medication, psychological support, psychiatric treatment.

The data were collected in a computerized medical record and analyzed in a totally anonymous way.

All new prisoners were screened for the suicide risk through the administration of the "Arboleda-Florez Check List" (Arboleda-Florez \& Holley, 1989). In all cases of first detention the Great Surveillance was activated; in cases of drug abuse the Service for Drug Addiciton (SerT) was contacted.

The doctor on duty visited the prisoners and collected urine samples for the research of the most common substances of abuse in order to prescribe the most appropriate pharmacological treatment. The specialist established the frequency of medical visits and, if necessary, established additional therapeutic-rehabilitative interventions with the involvement of a psychologist.

\section{Results}

\section{Socio-demographic information}

From April to December 2016, 93 prisoners (all males) were conducted in the Penitentiary of Pistoia: 12 (12.90\%) came from another prison; 81 (87.09\%) were free before the arrival. In this last group, 36 (38.70\% of total sample) were Italian, $12(12.9 \%)$ had the Moroccan nationality, 15 (16.12\%) Nigerian, 1(1.07\%) Iranian, 1(1.07\%) Hungarian, 3 (3.22\%) Tunisian, 1(1.07\%) Dominican, 2 (2.15\%) Romanian, 6 (6.45\%) Albanian, 1(1.07\%) Egyptian, 1(1.07\%) Pakistani, 1(1.07\%) Brazilian. The mean age of prisoners was 35 years (range 18-86 years) and the most represented age group was $25-34$ years $(30.10 \%, n=28) .16(17.2 \%)$ were homeless, 52 (55.91\%) were unemployed, 1 (1.07\%) was retired. Of the 93 newcomers, 32 declared to use drugs; 7 of them declared also the alcohol abuse. Three detainees claimed only the alcohol abuse. 9 prisoners were already assisted by the Service for Drug Addiction when they have been arrested.

\section{Clinical evaluation}

77 (82.79\%) were positive for at least 1 item of the Arboleda-Florez Checklist. The overall level of suicidal risk, was medium in most cases (medium risk = positivity for clinical evaluation and negative Checklist, or negativity for clinical evaluation and positive Checklist(1)).

The measures of great surveillance were disposed for 67 prisoners: 45 because it was their first incarceration, 1 for psychological distress, 6 for the evaluation and monitoring of adaptation, 4 for self-injurious risk, 1 for behavioral alterations induced by alcohol, 9 for drug/alcohol dependence, 1 because of the particular type of crime. In 2 cases, the multidisciplinary staff ordered to increase the level of custodial surveillance to greatest surveillance: in one case because of the psychopathological decompensation of the inmate, in the other case because of the severe alcoholinduced behavioral changes. 
The Greatest Surveillance measures for high suicide risk were 3: in 2 cases the detainees showed important self-injurious behaviors and in one case the detainee presented more risk factors (beyond those detected by the check list) such as the advanced age, the severity of the crime, and the significant concomitant medical conditions.

13 inmates needed a specific pharmacological treatment prescribed by the psychiatrist. In 6 cases the prescription was the prosecution of a previously prescribed therapy (patients already treated with specific medications for bipolar II disorder, depressive disorder, claustrophobia, Generalised Anxiety Disorder). In 6 cases the prescription was given "ex novo" (1 for paranoid schizophrenia, 1 for intense anxiety in patients with a history of self-injurious acts, 1 for behavioral changes in a patient with suspected diagnosis of schizophrenia, 2 for self-injurious acts, 1 for the lack of impulse control). In one case the treatment was prescribed after further talks with the inmate, which began to manifest self-injurious ideation.

Symptomatic therapy for mild anxiety and insomnia was prescribed in 29 cases: 21 after the first visit; 8 subsequently. A psychological support was furnished to 23 prisoners who didn't need the prescription of psychotropic medication, but only an emotional support.

\section{Discussion and conclusions}

Self-injurious behavior involving deliberate self-harm and suicide attempts by inmates while under custodial authority is a major problem for prisons and jails (prevalence, legal obligation for suicide prevention, and stress for officers) (Lohner \& Konrad, 2006). So, in penal settings it is important to be able to quickly discriminate which kinds of self-destructive behaviors carry a larger suicide potential and which inmates present a greater suicide risk. The Suicide Checklist by Arboleda-Florez, was designed for use by the nursing staff of the Penitentiaries to provide a screening process which would be: (a) reliable; (b) valid (within the broad constraints and difficulties inherent in any attempt to predict dangerousness to self); (c) standardized; (d) quick and feasible to implement; and (e) a combination of clinical and past history variables (Arboleda-Florez \& Holley, 1988).

In 2004 Shaw et al., conducted a study on prisoners judged to have died by suicide. But their findings had important limitations. Clinicians and other prison personnel completing questionnaires may have been biased by their awareness of outcome, and this may have affected, in particular, their reporting of estimates of risk at last contact. Suicide rates were not standardized by age and were not strictly comparable with the general population (Shaw et al., 2004).

In 2004 in Canada, was performed a similar study: however, the data collected for the research from volunteers, correctional staff, general inmate population, and professional staff were too low and the statistical analyses were not practical (Hall \& Gabor, 2004).

In Italy, Preti et al., monitored the attempted suicides and other self-harming behaviours that occurred in Italian prisons from 1990 to 2002. They showed in their study that the suicide rates in Italian prisons were constantly about ten times higher than among the general population, but over time they did not increase significantly despite nearly a doubling in the absolute number of inmates. Moreover, the rate of completed suicides in overcrowded prisons was about ten times higher than in non-overcrowded ones. Foreigners (non-EU citizens mostly) were twice at risk to self-harm than residents. The authors highlighted that a better identification of the people suffering from mental disorders and a reduction in prison overcrowding are two key issues that need to be implemented to reduce the impact of suicide and self-harming behaviours among convicts (Preti \& Cascio, 2006).

Several prison suicide prevention strategies in the US, UK, and Australia, have been developed partly in response to what is known about the epidemiology of suicide in prisoners and in-depth analyses of the prison and clinical records of inmates thought to have taken their own lives (Konrad et al., 2007) .

Our choice to use this tool could be debatable. However, a recent review showed that the effectiveness of suicide screening tools and checklists is not strong (O'Connor et al., 2013), with high false-positive and false-negative rates (Marzano et al., 2016). But their use is generally considered to be an important component of any comprehensive prison suicide prevention policy because it can help identify high-risk groups and may reduce suicide risk (Konrad et al., 2007).

The evaluation made at the Penitentiary of Pistoia identified 67 prisoners at risk (so it was disposed the great surveillance) and 3 at elevated risk (so it was disposed the greatest surveillance). A number of studies have found that prisoners making nearlethal attempts in prison are more likely than other prisoners to have a history of prior self-harm and suicide attempts (both in prison and outside), and to have received psychiatric hospital inpatient and outpatient treatment (Marzano et al., 2010; Rivlin et al., 2012). Other historical factors relate to adverse life events (Marzano et al., 2016; Levorato et al., 2017), including a family history of suicide (Marzano et al., 2016; Marzano et al., 2010).

Studying survivors of near-lethal suicide attempts (Rivlin et al., 2012), the mental health problems, both current and historical, were specifically identified as factors associated with, and potentially precipitating, nearlethal suicide attempts in prisoners. In previously published studies male prisoners were disproportionately affected by major depressive symptoms (Lohner \& Konrad, 2006) psychosis, anxiety (including posttraumatic stress disorder 
[PTSD]) and drug misuse disorders. In both men and women inmates, comorbidity of disorders was common and significantly associated with near-lethal attempts (Marzano et al., 2010). There were high levels of self-reported aggression, impulsivity, hostility, childhood trauma, and hopelessness (the latter also being a significant risk factor in other research (23)), and lower levels of social support and self-esteem (Marzano et al., 2016).

This is the reason why, a psychological support was provided to 23 prisoners who didn't need the prescription of psychotropic medication, but only a emotional support, and a symptomatic therapy for mild anxiety and insomnia was prescribed in 29 cases. 13 inmates needed a specific pharmacological treatment prescribed by the psychiatrist.

Preventing suicide is difficult, especially in a prison setting. While certain aspects of prison life should make suicide more easily preventable than in the community (e.g., by allowing greater monitoring of those at risk, and limiting access to means of suicide), others (e.g., bullying, social isolation, and lack of purposeful activity) may increase risk in an already high-risk population by virtue of their elevated levels of psychiatric morbidity, substance abuse, trauma, and social isolation. However, a previous research has shown that comprehensive multifactored suicide prevention programs and peer-focused suicide prevention initiatives can reduce the number of suicides and suicide attempts in prisons by tackling potentially modifiable environmental, clinical, and psychosocial factors (Barker et al., 2014).

The most important limits of our study are represented by the small sample size that could not totally represent the population of inmates and by the tool used to identify subjects at risk. However the use of the Arboleda Florez Checklist, although with its limits, let us identify suicide behaviors and prevent suicidal behaviors and self injuries among our sample.

In conclusion, our study showed that the protocol introduced in 2014 was able to manage in a good way the suicide risk in the Penitentiary of Santa Caterina, in fact no suicide occurred in the examined period of time. However, studies covering longer periods of time and with the application of the protocol to other realities could furnish more reliable results about its efficacy and we hope to continue monitoring the efficacy of the protocol with further ecological investigations. Although we sometimes lack the ability to accurately predict if and when an inmate will attempt or commit suicide, prison officials and correctional, health care, and mental health personnel are in the best position to identify, assess, and treat potentially suicidal behaviour. Even though not all inmate suicides are preventable, many are, and a systematic reduction of these deaths can occur if comprehensive suicide prevention programmes are implemented in correctional facilities throughout the world.

\section{Acknowledgements}

Not applicable.

Funding

Not applicable.

Availability of data and materials

Please contact author for data requests.

\section{Authors' contributions}

AF had the idea for the article, collaborated in performing the study, carried out the data analysis and collaborate in writing the article. LB participated at the design of the study, collaborated in writing the article and helped to conceptualize ideas. LR participated at the design of the study, collaborated in writing the article and helped to conceptualize ideas. MMancino collaborated in writing the article and helped to conceptualize ideas. MMeschi collaborated in writing the article and helped to conceptualize ideas. NN collaborated in writing the article and helped to conceptualize ideas. GT had the idea for the article, collaborated in performing the study, carried out the data analysis and collaborate in writing the article. All authors read and approved the final manuscript.

\section{Ethics approval}

A multidisciplinary staff, guided by the Health Director and the Director of the Penitentiary supervised the correctness of the procedure. An informed consent was signed by all the participants before being included in the study. The need for approval was considered not necessary because data were analyzed in a totally anonymous way.

\section{Consent for publication}

Not applicable.

\section{Competing interests}

The authors declare that they have no competing interests.

\section{Publisher's Note}

Springer Nature remains neutral with regard to jurisdictional claims in published maps and institutional affiliations.

\section{Author details}

${ }^{1}$ Psychiatric rehabilitation technician, Azienda Toscana Centro, Pistoia, Italy. ${ }^{2}$ Azienda Toscana Centro, Pistoia, Italy. ${ }^{3}$ Post Graduate School of Public Health, University of Siena, Siena, Italy. ${ }^{4}$ Department of Molecular and Developmental Medicine, Area of Public Health, University of Siena, 2 Via A. Moro, 53100 Siena, Italy.

Received: 19 June 2017 Accepted: 22 November 2017

Published online: 15 December 2017

\section{References}

Arboleda-Florez J, Holley HL (1988) Development of a suicide screening instrument for use in a remand centre setting. Can J Psychiatry 33(7):595-598 Epub 1988/10/01

Arboleda-Florez J, Holley H (1989) Predicting suicide behaviours in incarcerated settings. Can J Psychiatry 34(7):668-674 Epub 1989/10/01

Baillargeon J, Penn JV, Thomas CR, Temple JR, Baillargeon G, Murray OJ (2009) Psychiatric disorders and suicide in the nation's largest state prison system. J Am Acad Psychiatry Law 37(2):188-193 Epub 2009/06/19

Barker E, Kolves K, De Leo D (2014) Management of suicidal and self-harming behaviors in prisons: systematic literature review of evidence-based activities. Arch Suicide Res 18(3):227-240 Epub 2014/03/13

Daigle MS, Daniel AE, Dear GE, Frottier P, Hayes LM, Kerkhof A et al (2007) Preventing suicide in prisons, part II. International comparisons of suicide prevention services in correctional facilities. Crisis 28(3):122-130 Epub 2007/11/13

Fazel S, Cartwright J, Norman-Nott A, Hawton K (2008) Suicide in prisoners: a systematic review of risk factors. J Clin Psychiatry 69(11):1721-1731 Epub 2008/11/26

Fazel S, Grann M, Kling B, Hawton K (2011) Prison suicide in 12 countries: an ecological study of 861 suicides during 2003-2007. Soc Psychiatry Psychiatr Epidemiol 46(3):191-195 Epub 2010/02/09

Felthous AR (2011) Suicide behind bars: trends, inconsistencies, and practical implications. J Forensic Sci 56(6):1541-1555 Epub 2011/08/11 
Frangione A, Troiano G, lapichino S, D'Anza V, Cerretini I, Luporini A, Mancino M, Russo C, Nante N (2016) Preventing prisoners' suicide and autolesionism in Italy. Eur J Pub Health 26(Suppl. 1):24

Gambaro V, Argo A, Cippitelli M, Dell'Acqua L, Fare F, Froldi R et al (2014a) Unexpected variation of the codeine/morphine ratio following fatal heroin overdose. J Anal Toxicol 38(5):289-294 Epub 2014/04/15

Gambaro V, Argo A, Cippitelli M, Dell'Acqua L, Fare F, Froldi R, Guerrini K, Roda G, Rusconi C, Procaccianti P (2014b) Unexpected variation of the codeine/ morphine ratio following fatal heroin overdose. J Anal Toxicol:1-6

Gore SM (1999) Suicide in prisons. Reflection of the communities served, or exacerbated risk? Br J Psychiatry 175:50-55 Epub 2000/01/06

Hall B, Gabor P (2004) Peer suicide prevention in a prison. Crisis 25(1):19-26 Epub 2004/09/24

Kariminia A, Law MG, Butler TG, Corben SP, Levy MH, Kaldor JM et al (2007) Factors associated with mortality in a cohort of Australian prisoners. Eur J Epidemiol 22(7):417-428 Epub 2007/08/02

Katia Guerrini AA, Borroni C, Catalano D, Dell'Acqua L, Farè F, Procaccianti P, Roda G, Gambaro V (2013) Development and validation of a reliable method for studying the distribution pattern for opiates metabolites in brain. J Pharm Biomed Anal 73:125-130

Konrad N, Daigle MS, Daniel AE, Dear GE, Frottier P, Hayes LM et al (2007) Preventing suicide in prisons, part I. Recommendations from the International Association for Suicide Prevention Task Force on suicide in prisons. Crisis 28(3):113-121 Epub 2007/11/13

Levorato S, Bocci G, Troiano G, Messina G, Nante N (2017) Health status of homeless persons: a pilot study in the Padua municipal dorm. Annali di igiene : medicina preventiva e di comunita 29(1):54-62 Epub 2017/01/10

Lohner J, Konrad N (2006) Deliberate self-harm and suicide attempt in custody: distinguishing features in male inmates' self-injurious behavior. Int J Law Psychiatry 29(5):370-385 Epub 2006/06/20

Marzano L, Fazel S, Rivlin A, Hawton K (2010) Psychiatric disorders in women prisoners who have engaged in near-lethal self-harm: case-control study. $\mathrm{Br} J$ Psychiatry 197(3):219-226 Epub 2010/09/03

Marzano L, Hawton K, Rivlin A, Smith EN, Piper M, Fazel S (2016) Prevention of suicidal behavior in prisons. Crisis 37(5):323-334 Epub 2016/06/10

Mercurio I, Troiano G, Melai P, Agostinelli V, Simone R, Nante N, Bacci M (2016a) The analysis of the keratin matrix as a new tool to evaluate the epidemiology of drug use in Perugia (Italy): a cross sectional study. Epidemiol Biostatistics and Public Health 13(2):e11732-e111/7

Mercurio I, Troiano G, Melai P, Zappulla M, Agostinelli V, Nante N, Bacci M (2016b) A 10 year post-mortem analysis of keratin matrix in Perugia (Italy): focus on cocaine involvement in several types of death. Aust J Forensic Sci. https://doi.org/10.1080/00450618.2016.1264479

Mercurio I, Troiano G, Melai P, Zappulla M, Carlini L, Nante N et al (2017) Hair testing for cocaine in living men: an epidemiological study on hair samples collected for various medico-legal purposes. Aust J Forensic Sci 18:1-9

O'Connor E, Gaynes B, Burda BU, Williams C, Whitlock EP (2013) Screening for suicide risk in primary care: a systematic evidence review for the US preventive services task force. Agency for Healthcare Research and Quality (US), Rockville

Opitz-Welke A, Bennefeld-Kersten K, Konrad N, Welke J (2013) Prison suicides in Germany from 2000 to 2011. Int J Law Psychiatry 36(5-6):386-389 Epub 2013/07/16

Preti A, Cascio MT (2006) Prison suicides and self-harming behaviours in Italy, 1990-2002. Med Sci Law 46(2):127-134 Epub 2006/05/11

Rabe K (2012) Prison structure, inmate mortality and suicide risk in Europe. Int J Law Psychiatry 35(3):222-230 Epub 2012/03/27

Rivlin A, Fazel S, Marzano L, Hawton K (2012) Studying survivors of near-lethal suicide attempts as a proxy for completed suicide in prisons. Forensic Sci Int 220(1-3):19-26 Epub 2012/02/07

Roda G, Liberti V, Arnoldi S, Argo A, Rusconi C, Suardi S et al (2013) Capillary electrophoretic and extraction conditions for the analysis of Catha Edulis FORKS active principles. Forensic Sci Int 228(1-3):154-159 Epub 2013/04/20

Shaw J, Baker D, Hunt IM, Moloney A, Appleby L (2004) Suicide by prisoners. National clinical survey. Br J Psychiatry 184:263-267 Epub 2004/03/03

Stefania Milione IM, Troiano G, Melai P, Agostinelli V, Nante N, Bacci M (2016) Drugs and psychoactive substances in the Tiber River. Aust J Forensic Sci. https://doi.org/10.1080/00450618.2016.1212270

Troiano G, Mercurio I, Melai P, Nante N, Lancia M, Bacci M (2017) Suicide behaviour and arsenic levels in drinking water: a possible association? Egyptian J of Forensic Sci 7(1):2.

WHO (2014) Preventing suicide: A global imperative, p 92

\section{Submit your manuscript to a SpringerOpen ${ }^{\circ}$} journal and benefit from:

- Convenient online submission

- Rigorous peer review

Open access: articles freely available online

- High visibility within the field

Retaining the copyright to your article

Submit your next manuscript at $>$ springeropen.com 